(C) 2016

O. Gulay, candidate of biologycal sciences

Institute of Agroecology and Environmental Management of National Ukrainian Academy of Agrarian Sciences

O. Zhukorskyi, doctor of agricultural science

National Ukrainian Academy of Agrarian

Sciences

V. Gulay, candidate of agricultural

science Vynnychenko State

Pedagogical University

\title{
DYNAMICS OF GROWTH OF CULTURES OF PATHOGENIC BACTERIUM IN CONDITIONS OF ASTATICISM OF THERMAL FACTOR
}

The purpose. To determine influence of day-night temperature variations upon dynamics of growth of cultures of pathogenic bacterium Erysipelothrix rhusiopathiae. Methods. In model experiments in vitro dynamics of growth of bacteria E. rhusiopathiae in conditions of temperature variations $3,5,10,15$ and $20^{\circ} \mathrm{C}$ is probed at daily average temperature $23^{\circ} \mathrm{C}$. Control series was incubated at a constant temperature of $23^{\circ} \mathrm{C}$. Results. At periodic fluctuation of ambient temperature within the limits of $3-5^{\circ} \mathrm{C}$ from optimum stationary level $\left(23^{\circ} \mathrm{C}\right)$ the content of $E$. rhusiopathiae in cultures increases in $1,4-1,6$ times in comparison with the control. At increase of range of temperature variations up to $15^{\circ} \mathrm{C}$ indexes of growth of bacterial cultures drop in comparison with the maximum ones. Day-night temperature variations $\left(20^{\circ} \mathrm{C}\right)$ negatively influenced growth of cultures of experimental sort of microorganisms. Conclusions.

Stationary conditions with an index of temperature $23^{\circ} \mathrm{C}$ are not an ecological optimum for bacteria $E$. rhusiopathiae. Periodic deflexions rom the mentioned index over the range of $3-5^{\circ} \mathrm{C}$ may be considered as ecological optimum.

Astaticism of temperature of water of flat ponds is favorable for growth of pathogenic bacterium E. rhusiopathiae.

Key words: Erysipelothrix rhusiopathiae, astaticism of thermal factor, growth of crops.

The objects of the environment (water, soil) are the place of existence and reservation of a number of pathogenic microorganisms, which can get into the body of people or animals under certain conditions, causing the development of an infectious disease. One of 
these types of bacteria is Erysipelothrix rhusiopathiae (Migula, 1900), which is often found in reservoirs, soils, as well as during the examination of various species of wild and farm animals [1, 2].

According to the scientific literature, abiotic environmental factors play an important role in the existence of pathogenic microorganisms, the most important ones being temperature, light, active reaction of the environment, humidity, salt regime, etc. [2]. Thus, most authors believe that the optimum temperature for the development of $E$. rhusiopathiae is the temperature of

$+37.5^{\circ} \mathrm{C}$, which is recommended for the cultivation of these microorganisms in laboratories [2-5]. However, the experimental research conducted by $\mathrm{D}$. Yu. Halla (1965) proved that it is the temperature of $+23,0^{\circ} \mathrm{C}$ that should be considered as the optimum temperature for $E$. rhusiopathiae [6]. This temperature index is recorded in the upper layers of fresh water reservoirs during the warm period of the year. In contrast to the stationary temperature conditions of the experiment, periodic daily fluctuations of temperature numbers are observed in nature, which undoubtedly affects the existence of aquatic organisms. In the scientific literature, there are data indicating a beneficial effect of periodic fluctuations in the conditions of abiotic environmental factors on hydrobionts (mollusks, crustaceans, fish, etc.) [7-10].

Our objective was to determine the effect of daily temperature fluctuations in the water environment on the growth dynamics of E. rhusiopathiae bacteria.

During the in vitro model experiments, the growth dynamics of E. rhusiopathiae bacteria was studied in the conditions of daily temperature fluctuations of $3,5,10,15$ and $20^{\circ} \mathrm{C}$. Prior to the experiments, the initial bacteria culture had been grown for 30 days on a cardiovascular broth (AES Chemunex, France) at the temperature of $+23.0^{\circ} \mathrm{C}$ with regular re-seeding every 5 days.

The initial content of $E$. rhusiopathiae in all experimental specimen 
groups and the control was the same. Each row of test tubes was placed in the conditions of daily temperature variations: $3^{\circ} \mathrm{C}\left(+21.5^{\circ} \ldots+24.5^{\circ} \mathrm{C}\right)$; $5 \stackrel{\circ}{ }\left(+20.5^{\circ} \ldots+25.5^{\circ}\right) ; \quad 10^{\circ} \quad\left(+18.0^{\circ} \ldots+28.0^{\circ}\right) ; 15^{\circ} \quad\left(+15.5^{\circ} \ldots+30.5 \circ \mathrm{C}\right)$

and $20 \div(+13.0 \ldots \ldots+33.0 \circ)$ with an average daily temperature of + $23.0^{\circ} \mathrm{C}$. The control row was cultivated at the constant temperature of $+23.0^{\circ} \mathrm{C}$. The content of

E. rhusiopathiae in the experimental and control specimens was determined every 4 hours during the period of 2 days.

The results were recorded by seeding test probes from the experimental and control specimens to the surface of the cardiovascular agar (AES Chemunex, France) in dilutions of $1 \times 10^{-1}, 1 \times 10^{-2}, 1 \times 10^{-3}$, $1 \times 10^{-4}, 1 \times 10^{-5}, 1 \times 10^{-6}$. After cultivating them at the temperature of $+36.7 \pm 0.3^{\circ} \mathrm{C}$ for 72 hours, the number of grown colonies was calculated, and the average number of colony- forming units (CFUs) of bacteria per $1.0 \mathrm{~cm}^{3}$ was counted.

The information indicating changes in the number of bacterial CFUs in the growth process of $E$. rhusiopathiae cultures in the conditions of daily temperature fluctuations and the control (stationary conditions) are given in Table. 1 . 
Table 1.

The number of bacterial CFUs in the growth process of $E$. rhusiopathiae cultures in the conditions of daily temperature fluctuations $\left(\times 10^{6}\right)$ $\mathrm{cm}^{3}$ )

\begin{tabular}{|c|c|c|c|c|c|c|}
\hline \multirow{2}{*}{ Hours } & \multicolumn{5}{|c|}{ (daily fluctuations of temperature, $\stackrel{\circ}{ } \mathrm{C}$ ) } & \multirow{2}{*}{ Control } \\
\hline & 3 & 5 & 10 & 15 & 20 & \\
\hline 4 & 9.6 & 6.2 & 1.8 & 0.0 & 0.0 & 4.3 \\
\hline 8 & 66.7 & 45.1 & 6.5 & 0.0 & 0.0 & 12.4 \\
\hline 12 & $\begin{array}{c}110 . \\
4\end{array}$ & $\begin{array}{c}102 . \\
8\end{array}$ & 17.3 & 3.9 & 0.0 & 35.9 \\
\hline 16 & $\begin{array}{c}153 . \\
6\end{array}$ & $\begin{array}{c}163 . \\
9\end{array}$ & 35.4 & 10.6 & 1.2 & 66.4 \\
\hline 20 & $\begin{array}{c}197 . \\
8\end{array}$ & $\begin{array}{c}248 . \\
2\end{array}$ & 56.2 & 19.8 & 1.7 & $\begin{array}{c}108 . \\
3\end{array}$ \\
\hline 24 & $\begin{array}{c}243 . \\
4\end{array}$ & $\begin{array}{c}297 . \\
5\end{array}$ & 81.6 & 25.1 & 2.5 & $\begin{array}{c}153 . \\
7\end{array}$ \\
\hline 28 & 252.5 & 311.3 & $\begin{array}{c}100 . \\
3\end{array}$ & 30.4 & 4.1 & 166.2 \\
\hline 32 & 258.1 & 324.7 & $\begin{array}{c}111 . \\
9\end{array}$ & 34.7 & 5.9 & 168.9 \\
\hline 36 & 255.7 & 328.2 & $\begin{array}{c}118 . \\
4\end{array}$ & 38.3 & 8.3 & 170.4 \\
\hline 40 & 262.8 & 331.9 & $\begin{array}{c}121 . \\
2\end{array}$ & 39.9 & 10.7 & 171.8 \\
\hline 44 & 260.3 & 334.0 & $\begin{array}{c}123 . \\
1\end{array}$ & 40.6 & 14.3 & 176.0 \\
\hline 48 & 263.5 & 337.1 & $\begin{array}{c}123 . \\
8\end{array}$ & 41.0 & 17.5 & 178.1 \\
\hline
\end{tabular}

The end of the lag phase and the beginning of the logarithmic growth phase for the cultures that evolved in the control and in the conditions of temperature fluctuations of 3,5 , and $10^{\circ} \mathrm{C}$ occurred after $\leq$ 4 hours. At the same time, with daily fluctuations of temperature at $15^{\circ} \mathrm{C}$, the logarithmic growth phase began after 8 hours, and at $20^{\circ} \mathrm{C}$ - only after 16 hours, which is respectively 2 and 4 times longer compared to the control. The end of the logarithmic growth phase of $E$. rhusiopathiae in the cultures that evolved at the temperature variation of $10^{\circ} \mathrm{C}$ and 
$15.0^{\circ} \mathrm{C}$ occurred 32 hours after the start of the experiment. With daily fluctuations of temperature within $3 \ldots 5 \stackrel{\circ}{ } \mathrm{C}$ and in the control, the logarithmic growth phase ended earlier - after 24 hours. Thus, anincrease in the range of daily temperature oscillations led to an increase in the duration of the logarithmic growth phase by 1.3 times. In the conditions of daily temperature fluctuations of $20.0^{\circ} \mathrm{C}$, this phase of bacterial arowth lasted more

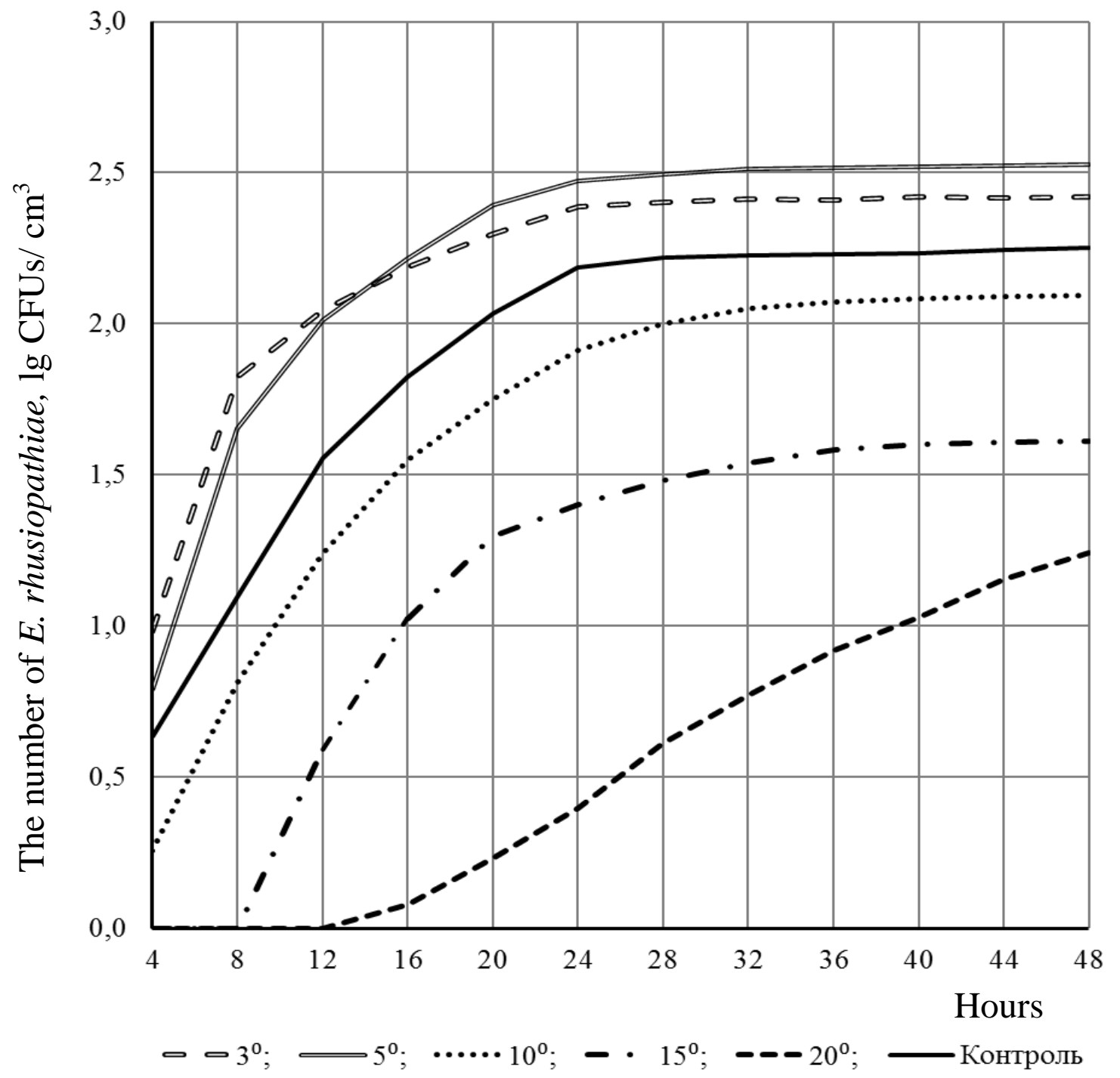

Fig. 1 Dynamics of $E$. rhusiopathiae cultures in the conditions of daily temperature fluctuations than 48 hours (Fig. 1).

The comparison of the amount of CFUs in $1.0 \mathrm{~cm}^{3}$ at the same points of the growth curves shows that there is an explicit tendency towards the increase in the culture density with daily temperature 
fluctuations of $3 \ldots 5^{\circ} \mathrm{C}$. Thus, 20 hours after the start of the experiment, the bacterial content in the specimens that were in the conditions of $3^{\circ} \mathrm{C}$ fluctuations was $82.6 \%$ higher than in the control, and in the conditions of 5o fluctuations - by $129.2 \%$. With daily fluctuations in the temperature of the environment over $5^{\circ} \mathrm{C}$, the rate of bacteria culture development and the accumulation of bacterial mass are reduced significantly. 28 hours after the beginning of the experiment, the content of the CFUs in the experimental samples compared with the control (100.0\%) was 151.9 $\%$ in case of $3^{\circ} \mathrm{C}$ temperature fluctuations; $187.3 \%$ under $5 \circ \mathrm{C}$ fluctuations; $60.4 \%\left(10^{\circ} \mathrm{C}\right.$ fluctuations); $18.3 \%$ (15을 $)$ or $2,4 \%$ in case of $20 \circ \mathrm{C}$ temperature fluctuations.

The obtained research results indicate that the accumulation of bacteria and the growth rate of bacteria cultures were maximal outside the stationary temperature conditions (control) - with daily fluctuations of this index within the range of $3 \ldots 5^{\circ} \mathrm{C}$, which should be considered an ecological optimum for rhusiopathiae.

\section{Conclusions.}

1. The ecological optimum for pathogenic E. rhusiopathiae bacteria is periodic temperature fluctuations within the range of $3-5^{\circ} \mathrm{C}$ rather than stationary conditions with the index of $23.0^{\circ} \mathrm{C}$.

2. Daily fluctuations of the temperature of the environment within $20^{\circ} \mathrm{C}$ have a negative effect on the growth of $E$. rhusiopathiae cultures. Although bacteria can develop in these conditions too.

3. Astatic indicators of water temperature in fresh water reservoirs during the warm period of the year create favorable conditions for the development of $E$. rhusiopathiae pathogenic bacteria.

\section{Bibliography}

1. Borisovich Yu.F. Infectious diseases of animals: Directory/Yu.F. Borisovich, L.V. Kirillov; under ed df Osidze - M .: Agropromizdat, 
1987. $-288 p$.

2. Hubalek Z. Microbial zoonoses and sapronoses/Z. Hubalek, I. Rudolf.- London - New York: Springer, 2011.- 271 p.

3. Voronin E.S. Roaring pigs: prevention and control measures / E.S. Voronin, M.V. Romanova. - Moscow: VNIITElagroprom, 1987.-42c.

4. Veterinary Microbiology and Microbial Disease/[Quinn P.J., Markey B.K., Leonard F.C., FitzPatrick E.S., Fannind S., Hartigan P.J.].West Sussex UK: Blackwell Science Ltd, 2002. - 1565 p.

5. Kislenko V.N. Veterinary Microbiology and Immunology: Textbook/Kislenko VN, Kolychev NM, Gosmanov RG - M .: GEOTAR - Media, 2012. - 752 pp.

6. Halla D.Yu. About the morphology of the pathogen of pork pig and listeria / D.U. Halla//Bulletin of Agricultural Science. - 1964. - №3. - P. 23 - 28.

7. Kuznetsov V.A. Astaticity of environmental factors as an ecological optimum for hydrobionts / V.A. Kuznetsov, V.S. Vechkanov, A.B. Ruchin//Materials of the 33rd Scientific Conference. - Saransk. 1997. - p. 28-30.

8. Verbitsky V.B. Temperature selection and avoidance of Daphnia magna Straus (Crustacea, Cladocera), acclimated to a constant temperature/VB Verbitsky, T. I. Verbitskaya//Proceedings of the RAS. Biological series .- 2012.- No. 1. - P. $109-114$.

9. Lobachev E.A. Astatichity of environmental factors as an ecological optimum for amphibians/E.A. Lobachev, VA Kuznetsov//Modern problems of evolution (a collection of reports). Ulyanovsk: Publishing House of Ulnovsky State. ped un-that - 2007. - P. 397 - 401.

10. Lukianov S.V. Influence of $\mathrm{pH}$ fluctuations on embryo-larval development of Siberian sturgeon Acipenser baerii Brandt/S.V. Lukianov, V.A. Kuznetsov//Bulletin of the Mordovian University. 2009. №1. - P. 239 - 242. 